\title{
Behavioral Finance Perspectives on Pakistan Stock Market Efficiency: Assessing the Prospect Theory Empirically with an Adaptive Pattern of Efficiency across Military and Democratic Regimes
}

\author{
Zareen Zafar $^{1 *}$, Danish Ahmed Siddiqui ${ }^{2}$
}

${ }^{1,2}$ Karachi University Business School, University of Karachi, Pakistan

Keywords:
Stock returns, KSE 100 Index,
Pakistan stock market,
Autocorrelation, Variance
ratio, Prospect theory

Received
15 April 2020
Received in revised form
15 July 2020
Accepted
15 July 2020

* Correspondence

zareenzafar2020@gmail.com

\begin{abstract}
This study is based on pragmatic creations to make the hypothetical frame focusing on behavioral finance pattern for finding the sagacity of investors, stock returns, and effectiveness of stock market performance. The research investigates an extensive extent of Pakistan stock market Returns data from June 1994 to December 2018 along with the two economic segments including the Military phase (1999-2008) and Democratic phase (1994-1998) (2009-2018) to determine the Pakistan Stock market efficiency. To this end, autocorrelation and variance ratio tests were performed on the returns (weekly based) KSE 100 index during overall period as well as for both the Military Phase and the Democratic phase using adaptive pattern of market competence. The weak efficiency tests show trends of a stock performance, and consequently developing of bounded-adaptive market effectiveness. These tests recognized the presence of asymmetric dynamic behavior of returns obviousness in calculation of risk and return associations during two political states. These confirmations offer provision to investors bounded adaptive rationality, behavior, vigorous behavior of stock return and as a result establishing effectiveness of bounded adaptive market.
\end{abstract}

\section{Introduction}

The study is based on the performance and efficiency measures of the Pakistan Stock Market with the collision of political changes on stock returns data by using Autocorrelation, variance ratio test 
on segmented data. The segments are divided after reviewing economic history of Pakistan after comparing political basis at a long extent of Stock returns data. The time period is selected as June 1994 to Dec 2018. The segments are named as overall, Military Phase and Democratic Phase. The rationale behind that is to make a clear elaboration of changes in stock returns seen in these segments which are quite cleared. The segments are divisions of year wise Stock returns data of Pakistan Stock market. By using excellent approach, the dimensionality of political instability can be measured effectively which is the first goal of the research. We use AR and VR as weak efficiency test indicators to calculate Pakistan Stock market efficiency with reference to political instability. To measure the efficiency of Pakistan stock market by using indicators (AR and VR) is considered the second goal. The third goal is to estimate that political instability in all three segments divided as overall, military phase, and democratic phase. Consequently, the era 19942018 indicates the clear picture of political instability and its impact on the Pakistan Stock Market efficiency. Our study contributes in this manner that the efficiency of Pakistan stock market illustrates different slots for the last 24 years as far as the eras are alienated. The gap analysis demonstrates that this sort of study has not been done before on the segmented data (overall, military phase, and democracy phase) with an aspect of stock returns to Pakistan.

The background of the study is based on capital markets that show a dynamic role in assembling unique assets and channels theme commendably for better financial efficiency. Then, the advancement of the capital market is the prime element of a country's financial development. In any public economy, market efficiency is of paramount importance when considering the delivery of scarce resources, as it performs a middle function of capital circulation from savers to investors through the price mechanism. When it comes to allocating resources to an unregulated economy, stock prices will find the right signal, i.e. the full collection of significance repression. In addition to this, behavioral finance clarifies why investors make logical mistakes in the investment decisionmaking process. It defines inadequacies such as under- and over-reaction by investors to the information. It explains how factors such as investor overconfidence, herding-behavior, and overoptimism affect the behavior of investors. Behavioral finance helps to illuminate markets where why and how can be inefficient.

It was regularly recognized in financial literature that an inefficient market cannot bring economic benefits just as much as an efficient market. Consequently, the center of financial studies is business effectiveness. The concept of stock market efficiency initially mentioned to allocation efficiency, which means that the stock market should allocate capital into the most creative sectors (Baumol, 1965). Fama (1970) categorized informational efficiency into three groups in his Efficient Market Hypothesis (EMH): weak-form efficiency; semi-strong form efficiency and strong-form efficiency. The EMH has delivered a testable framework that has been systematically practiced in the literature. There are several approaches for testing stock market effectiveness. The most effective approach to test stock return assessment is Autocorrelation, variance ratio.

The efficiency of Pakistan's stock market will be investigated using these tests. The following significant basis of the case has been taken into account in the progress of this study. First, the vast empiric literature has shown the testability of market efficiency in terms of the theoretical framework of the EMH. The EMH theory and the above methodologies subsequently function in studies of developed markets, developing markets, and emerging markets. In this study, the sufficiently empirical results provide functional benchmarks for comparative analysis. The study supports a comprehensive picture of the Pakistan Stock Market effectiveness. 
Instability and inefficiency are attributable to behavioral risks that are crucial for Asia to grow financial markets Finance behavior (Kim \& Nofsinger, 2008). The pragmatic judgment ensures that human beliefs and intends to optimize wealth as mentioned in expected utility theory idealize by Quiggin (1982). Fama (1965) demonizes the EMH as a business behavior analytical paradigm. Measures of wealth creation are of three types such as weak, semi-strong, and strong. The weak EMH shows that asset prices already reflect all prior information available to the public. EMH imagines securities are always cost-effective and reasonably priced.

The idea of efficient markets has been characterized by an intense theoretical and empirical discussion for more than a century because of its advancement in the 1960s (Ackert \& Deaves, 2009; Shefrin, 2001). However, after more than 40 years this fundamental issue stays baffled today (Verheyden, De Moore, \&Van Den Bossche, 2015). The question under discussion in this line of inquiries is that the market is fully efficient following the efficient market hypothesis (EMH) in the modern finance model or adaptive efficient in the behavioral finance paradigm as per the adaptive market hypothesis (AMH). While the AMH is still new with limited empirical support, market imperfection and inefficiency challenges are rising on the validity of EMH. AMH introduced by Lo (2004), idealized based on interdisciplinary theories consisting of bounded rationality, complex systems, evolutionary biology, and psychology of evolution. AMH is relevant to recognizing investor and market behavior variations in today's multi-faceted and vibrant market environment (Meier, 2014; Soufian, Forbes, \& Hudson, 2014). The efficiency tests show trends of a weak market efficiency adaptive pattern across different economic stages and market states. On the other hand, no such study was conducted in Pakistan. Many Pakistani studies have attempted to assess performance based on the EMH system (Irfan, Irfan, \& Awais, 2010) and the nature of efficiency low at Karachi Stock Exchange (KSE) (Omar, Hussain, Bhatti, \& Altaf, 2013).

Use of autocorrelation tests and the ARIMA model to check the KSE market's confidence and judgment suggested that both return series do not adopt the random walk rule, and the value of autocorrelation rejects the weak-form efficiency hypothesis (Rabbani, Kamal, \& Salim, 2013). Examining EMH in a time of wise analysis, findings indicated poor market performance for two classes of years 1999-2001 and 2005-2007. Though it (Zahid, Ramzan, \& Ramzan, 2012) was also designed to test Karachi stock exchange (KSE) weak-form efficiency using nonparametric tests. The return series was described as being non-normal in the skewness and kurtosis dimension. It is a special sort stock exchange analysis on Pakistan that deceives market output by utilizing the prospect theory. By using weak efficiency tests Autocorrelation and Variance ratio tests, we can observe the efficiency change in segmented data at a better edge with aspect to Pakistan stock market. Since behavioral financing is a fairly recent area of financial theory. We try to determine if, in the context of a developing economy, it is well appropriate to the suggested Pakistan stock market efficiency, an area that has saved some literature courtesy. This research adds to the literature by using tests on the autocorrelation and variance ratio to assess the effect of prospect theory on stock market performance. Also, it's a novel attempt to examine the complexity of political instability with Pakistan's future. We use AR and VR as weak efficiency test indicators to calculate the effectiveness of the Pakistan Stock market concerning political instability. Consequently, this research also takes a new step in exploring the connection between behavioral dynamics of performance and political transitions such as democracy and dictatorship by allowing for political stability in terms of regime changes. Pakistan has experienced both modes of governance among very few cases. 


\section{Literature Review}

The momentum of stocks depends greatly on how much the investor owns, and the forecasted returns depend on the variance found in Avramov and Chordia's (2006) analysis. Momentum strategy offers a chance to raise excess returns for knowledgeable investors by taking a long position on winner stocks. Momentum getting better because of the individual's overconfident behavior (Barberis, Shleifer, \& Vishny, 1998; Daniel, Hirshleifer, \& Subrahmanyam, 1998). Momentum gains may be built on liquid markets. Higher market liquidity or higher trade implies the prevalence of investor behavioral bias in the market (Hong \& Stein, 2007). Besides, the enduring momentum effect remains robust even after modification for risk factors (Chen, Chou, \& Hsieh, 2018).

Numerous researchers are of the view that investor sentiment not only describes the causes of the appearance of other risk factors like size, value, and momentum, it also affects stock returns directly and is one of the key determinants in clarifying the relationship between risk and return. For example, Statman (2014) found that investors classify stocks as good (big and growth) and poor (small and valuable) stock companies. They are depressing bad stock market prices and following the social contagion (Statman, Fisher, \& Anginer 2008). Uhl (2014) also established that behavioral biases could disguise the process of market adjustment. The sentimental wave can devalue stocks on the market; therefore, stocks do not necessarily represent all the knowledge available to the public at all times and entirely (Shefrin, 2001). Investors are suffering from the problem of overconfidence besides the limited rationality (Uhl, 2014; Huang, Heian, Zhang, 2008). These cognitive biases cause various kinds of financial-market irregularities. Verardo (2009) submitted that investors' heterogeneous beliefs lead to a strong momentum effect. To identify opportunities to make money, a pricing mechanism must be in place which incorporates investor sentiment. Sensory fluctuations can cause mispricing, and in a subsequent period, it will have an inverse effect on returns. The relationship between sentiment and return varies across safe and risky inventories. Risky stock yields are more likely to rely on sentimental shocks (Watanabe, Xu, Yao, $\& \mathrm{Yu}, 2013)$.

\section{Theoretical Framework}

\section{Efficient Market Hypothesis}

One of the important molds of traditional theories of finance is the effective market hypothesis. Fama (1970) evaluated an efficient market where many rational profit-maximizing individuals actively opposed each other and endeavored to estimate future market morals of individual securities, and where all relevant information is almost kindly achievable for all investors. As for the Efficient Market Hypothesis (EMH), and the efficient functioning stock market is intended to be externally and informational efficient; therefore, "safety prices at any point in time are an unbiased indication of all available information" on the estimated future cash flows of the security and the risk involved in buying such security (Reilly \& Brown, 2003, p. 57). The more efficient a market is estimated, the random series of its price fluctuates, with the most efficient market being the one in which prices are completely random and unpredictable (Fama, 1965; Lo, 2004). 


\section{Market Efficiency Tests}

The following are three types of market-efficiency tests:

\section{Weak Efficiency Test}

Analyzing the autocorrelation of returns for definite time lags is to check the weak form. If the returns time series contains linear dependencies, then the autocorrelation would yield about one. On this basis, a linear model may be expected to mimic the time series. Fama 's (1965) foundation definition will consider the EMH if uncorrelated returns occur. If the correlations do not automatically specify that the EMH should be rejected, as Sapusek (1998) explained, the filter technique method is the only way to prove the EMH.

\section{Semi-Strong Efficiency Test}

The semi-strong Efficiency Test describes abnormal returns which are routinely intended as the benefit differential between a certain stock and a benchmark or index stock (market-adjusted method). It is possible to obtain efficient market responses in terms of anomalous profits that do not await the relevant news. If stocks react substantially before the news appears, then the market would be inefficient. Abnormal returns can be expected if there are irregular changes in the variance from the return time series. According to the semi-strong form theory, these actions would gradually go down after the statement has been published. The unequal variation arises from the behavior of investors because they are unsure under the conditions of the "right" investment.

\section{Strong Efficiency Test}

The Strong Efficiency form can be verified by an insider trading analysis. Abnormal returns will document suspect insider trades before publishing appropriate news. Abnormal returns result is related to the semi-strong form. Finally, the empirical estimate of a strong type is nearly impossible, because it is difficult to identify individuals with a definite knowledge of the insider.

\section{Adaptive Market Hypothesis (AMH)}

The Adaptive Market Hypothesis (AMH) combines analysis of the economic and financial markets to investigate the real nature of market of participants' decisions. Lo (2004) believes that the evolutionary principles which apply to financial markets are especially promising. As a complex structure, the AMH is analogous to the recent progress in evolutionary game theory, evolutionary economics, and general economics. The EMH is the constraint of the steady-state while the AMH is the actual process of adaptation towards the final uniformity. In the fast-changing global financial markets, the markets are already moving towards another new equilibrium before any steady-state equilibrium is reached. We can only observe the $\mathrm{AMH}$ at work but never experience the true balance of the EMH on the actual financial markets. The risk-return relationship is likely to change over time with aspect to $\mathrm{AMH}$ and is path-dependent as market conditions regularly change.

\section{Prospect Theory}

The Prospect Theory was demonstrated by Kahneman and Tversky (2013), which shows the main step for using cognitive psychology to specify the various deviations in economic decision-making. The structure was made on individuals' irrationality. They present an analysis of the expected utility theory as an evocative model of risk-taking decision-making and expand a substitute model, called prospect theory. Prospect theory claimed that Interest is more allocated to gains and losses than to 
final assets; probabilities are also replaced by weights of decisions. The value function can be distinguished from a reference point on deviations and is normally concave for gains (implying risk aversion), normally convex for losses (risk search), and typically steeper for losses than gains (loss aversion) (see Figure 1). In general, decision weights are lower than the corresponding probabilities, except in the low probabilities range. Prospect theory explains that choices are based on a personal reference point that is independent of the state of wealth of the decision-maker. Personal reference points trigger a prospect frame, which affects the behavior of option. A kink exists at the reference point of prospect theory's value function, assuming individuals' weight losses at above twice that of gains.

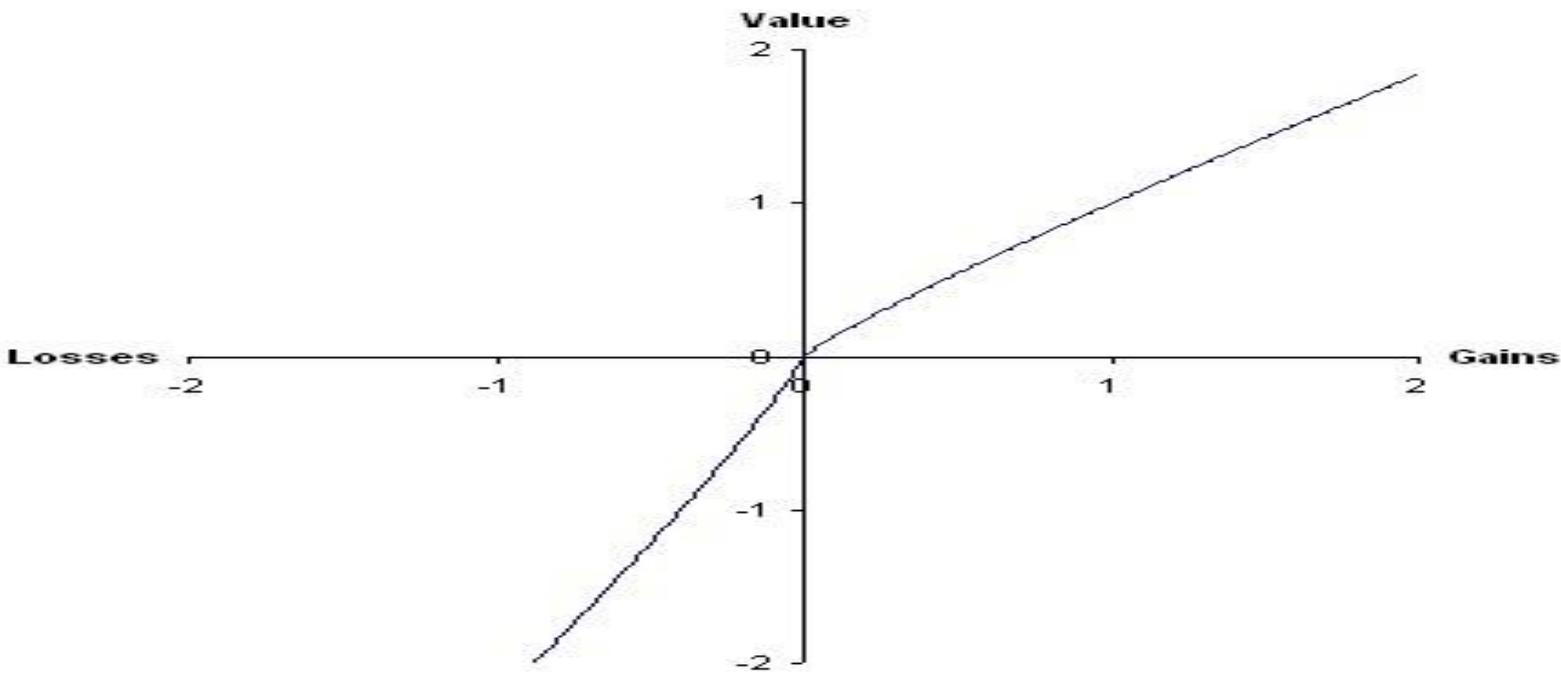

Figure 1. A hypothetical value function.

Tversky and Kahneman (1992) developed a new way of prospect theory to pay cumulative rather than distinguishable decision weights and in several respects extend the theory or any number of results, and requires various weighting functions for gains and losses. Two concepts are appealed to clarify the characteristic curvature of the interest function and the allocation functions, diminishing sensitivity, and loss aversion to principles. The historical evidence and the findings of a recent experiment support a distinctive four-fold risk pattern: risk aversion for gains and risk quest for high-probability losses; risk quest for gains and risk aversion for losses of low probability.

\section{Research Questions}

- Why do weak efficiency tests are used in the research study to manipulate Efficiency of Pakistan Stock market?

- What is the significance of prospect theory used to measure the adaptive pattern of efficiency among segmented data?

-Why do economically segmented data (Military and Democratic phases) are selected to show the distinction by using the long extent of stock returns data (1994-2018) of the Pakistan stock market?

\section{Method}

The research analysis is focused solely on the KSE 100 index market returns from the Pakistan Stock Exchange (PSX) over a long period of data from 1994 to 2018. PSX is considered to be one 
of the world's leading exchanges with an unwanted record of being Asia's best-performing stock exchange. PSX aims to retrieve that rank and has plans in place to make it a robust and efficient Stock Exchange at par or above par with other Stock Exchanges in the world. It is at the forefront of Pakistan's economy, being the only major institution helping capital formation in the country. The research examines the differentiation in two different regimes of Pakistan history. The regimes are selected after studying the economic history of Pakistan in detail. Pakistan's economic history shows different edges of growth as far as Pakistan Stock Exchange is concerned. That is why this unique work up at Stock returns of KSE 100 INDEX is selected to calculate the efficiency of PSX. The Stock Returns are taken weekly from June 1994 through Dec 2018 based on data maintained by Pakistan State Bank (SBP). Regimes are referred to as

1. Military Regime (Jan1999 to Dec2008)

2. Democratic Regime (June 1994 to Dec 1999) and (Jan 2009 to Dec 2018)

Efficiency of the Pakistan Stock Exchange is measured using the Autocorrelation and Variance Test ratio. Recent analyses of European business weakness include Smith and Ryoo (2003) and Worthington and Higgs (2004). Smith and Ryoo (2003) use the weekly data variance test for five European indexes from April 1991 to August 1998 and reject the hypothesis of a random walk for Greece, Hungary, Poland, and Portugal but find Turkey Next comes a random walk. Worthington and Higgs (2004) perform a very thorough analysis of twenty European nations, from August 1995 to May 2003, using various research methods, including serial correlation test, run test, Dickey-Fuller modified test, and a variance ratio test. We consider that all indexes are not well described by a normal distribution, and only five countries meet the most rigorous criteria for a random walk, namely Germany, Ireland, Portugal, Sweden, and the United Kingdom, while France, Finland, the Netherlands, Norway, and Spain meet just a few of the requirements for a random walk. Lo and MacKinlay (1990) also consider in the regular stock returns mostly positive autocorrelation which they attribute to non-synchronous trading or nontrading. Through regular returns of individual stocks and indices, Campbell et al. (1993) analyze the relationship between trading volume and serial correlation. The investigations provide limited investor rational and asymmetric dynamic stock return behavior. Behavioral finance shows that risk forces include fundamental and behavioral risk and that riskreturn relationships should be asymmetrically dynamic due to limited adaptive rationale of investors' thoughts and decisions. The Prospect theory point of view is used to affirm the asymmetric dynamic nature of stock returns at extreme losses and significant data distribution gains. The principle explains the investor determining based on losses and profits, and suffering losses, being more traumatic to humans than suffering profits.

\section{Calculation of Autocorrelation}

Autocorrelation is known as a common function in many datasets, referring to the correlation on similar artifacts between values of the same variable. It violates the instance independence critical statement which inspires most conventional models. Autocorrelation refers to the association of values on different items in the same equation. More formally, it is defined to a set of associated instance pairs (zi, zj) Z and a vector X based on these instances, and is the correlation between $\mathrm{X}$ values on those instance pairs. The AR test is conducted in the first study. The AR tests consider the coefficient of serial correlation between a sequence of returns and their lagged value, with the null hypothesis; $A R=0$ for all lag. The effort is to learn if the return series is a sense that it will 
exhibit zero behavior of autocorrelation. It shows a predictability overview of stock returns based on the information from its past series. Autocorrelation is intended from this model which is marked as Equation 1:

$$
\mathrm{Rt}=\alpha \mathrm{t}+\beta 1 \mathrm{Rt}-1+\varepsilon \mathrm{t}(\text { Equation } 1)
$$

\section{Calculation of Variance Ratio Test}

Lo and MacKinlay (1988) proposed the test of variance ratio, which can discern many important alternative stochastic processes. Lo and MacKinlay's (1988) variance ratio check is based on the property that a random walk Xt's variance of increments is constant in its data interval. That means the variance of $(\mathrm{Xt}-\mathrm{Xt}-\mathrm{q})$ is q times the variance of $(\mathrm{Xt}-\mathrm{t}-1)$. Therefore, the $\mathrm{RWH}$ can be checked by comparing $1 / \mathrm{q}$ times the variance of $(\mathrm{Xt}-\mathrm{Xt}-\mathrm{q})$ to the variance of $(\mathrm{Xt}-\mathrm{Xt}-1)$. Suppose $\mathrm{Pt}$ is the exchange rate at time $\mathrm{t}$ and let a random walk series, $\mathrm{Xt}$ is the natural logarithm of $\mathrm{Pt}[\mathrm{Xt} \mathrm{Pt} \ln =]$. The variance ratio, $\mathrm{VR}(\mathrm{q})$ is defined as: (1) VR q $=\Sigma \sigma 2 \mathrm{c}(\mathrm{q}) / \Sigma \sigma 2 \mathrm{a}$ (q) (2) where qs2 is $1 / \mathrm{q}$ times the variance of $(\mathrm{Xt}-\mathrm{Xt}-\mathrm{q})$ and (1) s2 is the variance of (Xt $-\mathrm{Xt}-1)$. The null hypothesis is that VR (q) is not statistically different from 1 . The equations to calculate (1)s2 and qs2 are as follows.

$$
\operatorname{VR}(\mathrm{q})=\Sigma \sigma 2 \mathrm{c}(\mathrm{q}) / \Sigma \sigma 2 \mathrm{a}(\mathrm{q})
$$

Homoscedasticity means different response variable values have the same variation in their errors regardless of the predictor variables. In practice, this assumption is false i.e. the errors are heteroscedastic if the response variable will differ on a large scale. To test for the heterogeneous variance of error, or whether a residual pattern contradicts homo model assumptions and to test for heterogeneous error variance, or where a residual pattern violates homoscedasticity model assumptions (the error is similarly variable along the 'best fit axis' for all x points), it is reasonable to look for a 'fanning effect' between residual error and expected values. This is to observe that when plotted against the predictive variables, there will be a systematic change in the absolute or squared residuals. Errors are not distributed uniformly around the regression axis. Heteroscedasticity results in averaging distinguishable variances across the points in order to produce a single variance that reflects inaccurately all the line variances. In consequence, residuals appear clustered and spread apart for larger and smaller values for points along the linear regression line on their expected plots, and the mean squared error for the model would be incorrect. Simple linear regression estimation methods provide less precise estimates of parameters and deceptive inferential quantities such as standard errors when there is a substantial heteroscedasticity.

\section{Results}

\section{Descriptive Statistics of Market Returns}

Table 1 sets out concise return statistics. Such findings provide proof of productivity in the multifunctional industry. Table 1 also displays the equity test findings by using ANOVA F-mean test, Chi-square for the median, Bartlett for the variance. The asymmetry of the index series distribution revealed a non-normal distribution with the help of Skewness statistics measures since the data shows the positive skewness. Kurtosis statistics and the importance of Jarque - Bera statistics also justify the non-normal distribution behavior 
(Bai \& Ng, 2005). Kurtosis notes the central peak's height and sharpness, similar to that of a regular bell curve.

Skewness, in mathematics, is a function of the asymmetry of a random variable's distribution of probability over its mean. Skewness reflects the sum and direction of skew (departure from horizontal symmetry). The check values for skewness may be positive or negative, or even unknown. When skewness shows 0 , the data is perfectly symmetrical, even though it is very rare for real-world details. As thumb rule overall, if the measure of skewness indicates less than -1 or more than 1 , the distribution is extremely distorted. If the skew test shows between -1 and -0.5 or between 0.5 and 1 , the distribution is skewed in moderation. If the skewness measure is between 0.5 and 0.5 , the distribution is symmetrical.

Table 1

Descriptive Statistics of Market Returns

\begin{tabular}{cccc}
\hline Statistics & Overall & Military Phase & Democracy Phase \\
\hline Mean & 0.01 & -0.00 & 0.01 \\
Median & -0.00 & -0.00 & -0.00 \\
Maximum & 16.63 & 0.22 & 16.63 \\
Minimum & -0.12 & -0.12 & -0.11 \\
Std. Dev. & 0.45 & 0.03 & 0.58 \\
Skewness & 36.09 & 1.17 & 28.26 \\
Kurtosis & 1311.69 & 7.25 & 802.35 \\
Jarque-Bera & 9512 & 511.13 & 2164 \\
Probability & 0.00 & 0.00 & 0.00 \\
Sum & 14.55 & -1.52 & 16.07 \\
Sum Sq. Dev. & 278.23 & 0.80 & 277.26 \\
Observations & 1329 & 520 & 809 \\
Mean & & & 0.00 \\
Median & NA & 0.00 & 0.00 \\
Variance & NA & 0.01 & $6.58 \mathrm{E}-09$ \\
\hline
\end{tabular}

\section{Autocorrelation Test Results}

Table 2 presents the results of the AR test. The overall results are insignificant that is there is no autocorrelation between a series of returns and its lagged value for the null hypothesis $A R=0$. In democracy phase, results are insignificant and this shows that there is no autocorrelation between a series of returns and its lagged value. Results specify that due to no autocorrelation, null hypothesis is accepted for the overall and democracy phase. But in the military phase, results are significant that indicate that there is autocorrelation among the series of returns and its lagged value for the null hypothesis $\mathrm{AR}=1$. Results indicate that there is autocorrelation, so the null hypothesis is rejected for the military phase. Table 2 shows the values for autocorrelation of all three regimes. Table 2

Autocorrelation Test Results

\begin{tabular}{cccc}
\hline Statistics & Overall & Military Phase & Democracy Phase \\
\hline Lag (1) & 0.00 & $11.53^{*}$ & 0.00 \\
Lag (2) & 0.00 & $16.01^{*}$ & 0.01 \\
Lag (3) & 0.01 & $16.43^{*}$ & 0.01 \\
Lag (4) & 0.02 & $17.18^{*}$ & 0.02 \\
Lag (5) & 0.02 & $19.69^{*}$ & 0.02 \\
Lag (6) & 0.02 & $20.40^{*}$ & 0.02 \\
Lag (7) & 0.02 & $21.50^{*}$ & 0.02 \\
$\operatorname{Lag}(8)$ & 0.03 & $21.51^{*}$ & 0.03 \\
$\operatorname{Lag}(9)$ & 0.04 & $22.11^{*}$ & 0.03 \\
$\operatorname{Lag}(10)$ & 0.04 & $24.04^{*}$ & 0.03 \\
$\operatorname{Lag}(11)$ & 0.04 & $24.16^{* *}$ & 0.03 \\
$\operatorname{Lag}(12)$ & 0.04 & $24.46^{* *}$ & 0.04 \\
\hline
\end{tabular}




\section{Graphical Presentation of Autocorrelation in All Three Regimes}

\section{Graph 1}

Figure 2 shows the autocorrelation in overall period with increasing and decreasing trends for the time period of 1996-2018.

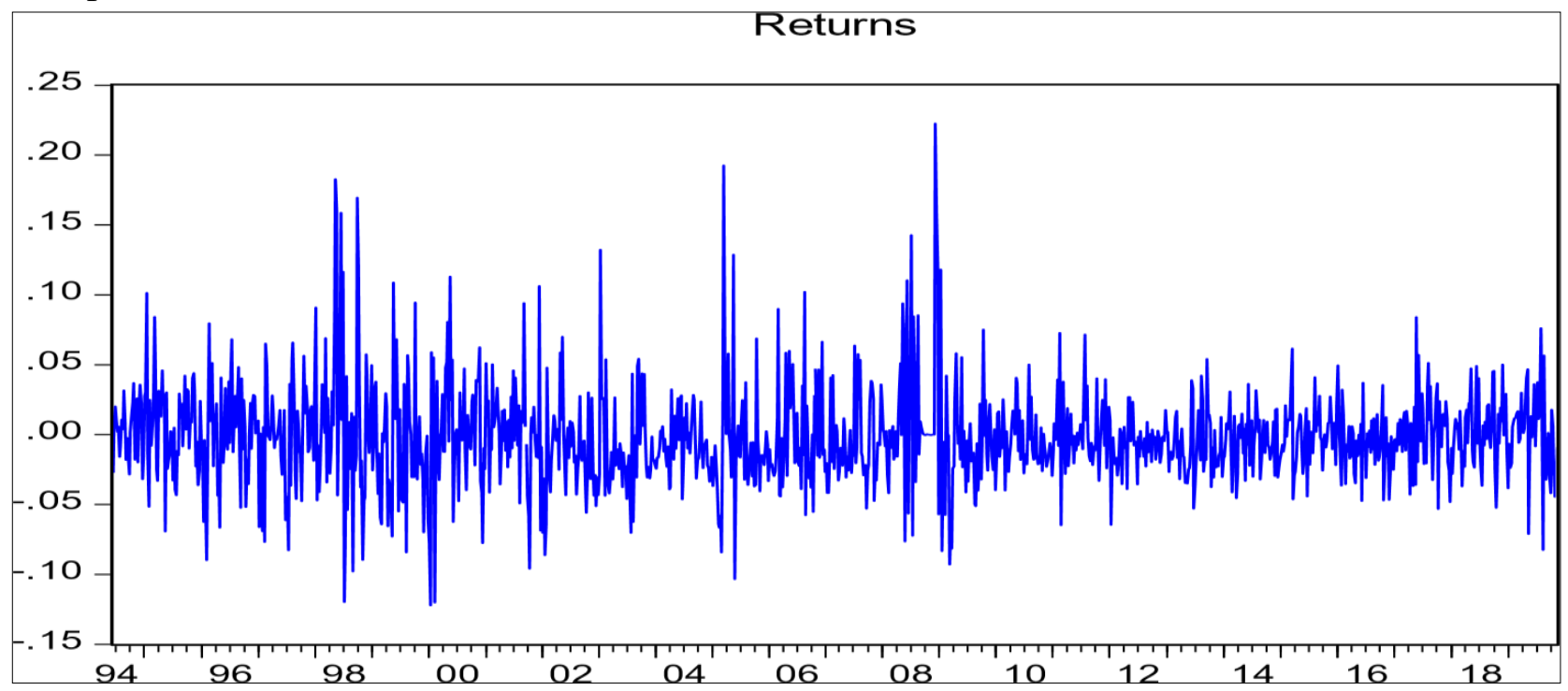

Figure 2. Autocorrelation for overall regime

\section{Graph 2}

Figure 3 shows the autocorrelation in military period with increasing and decreasing trends for time period 1999 to 2008 .

\section{Returns}

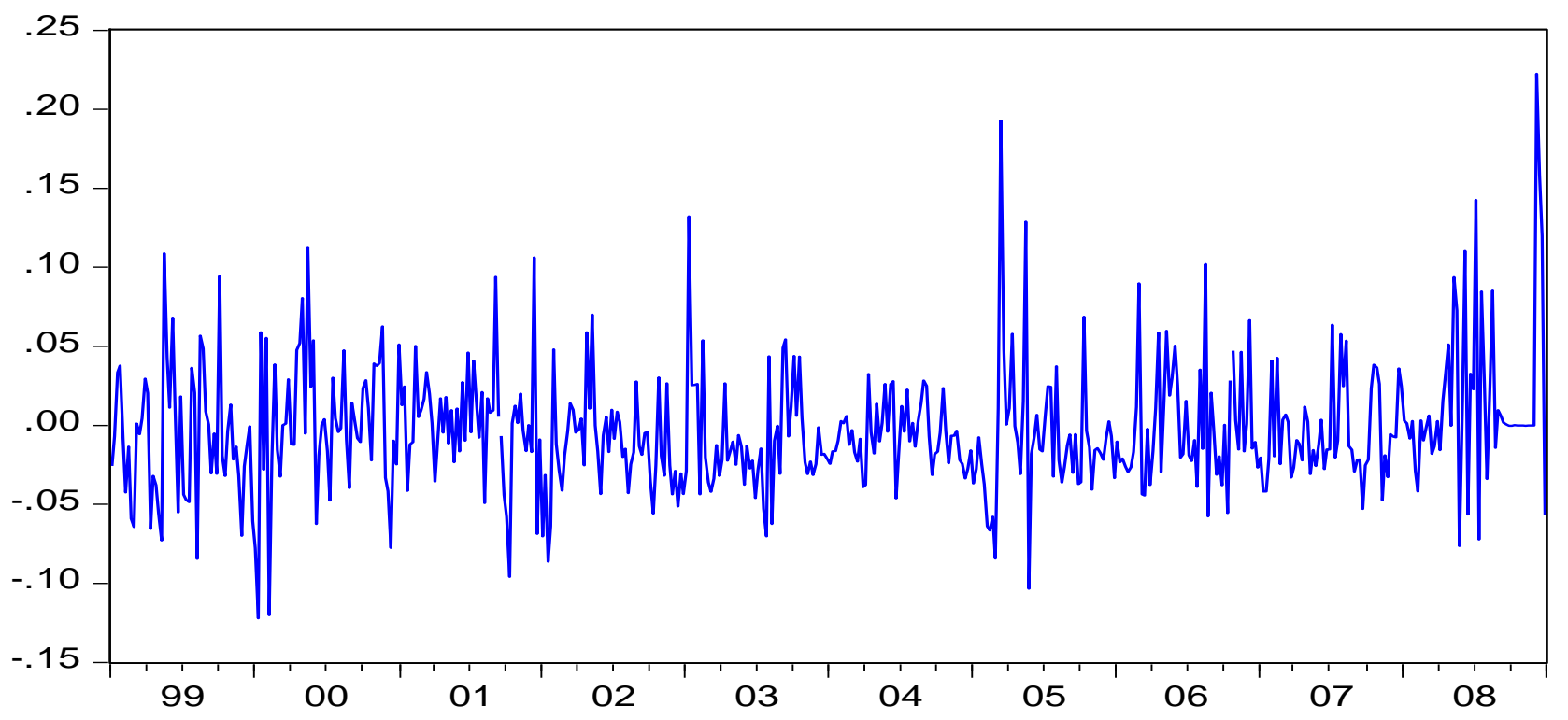

Figure 3. Autocorrelation for military regime 


\section{Graph 3}

Figure 4 shows the autocorrelation in democratic period with increasing and decreasing trends of the time period (1994 to 1998) (2009 to 2018).

\section{Returns}

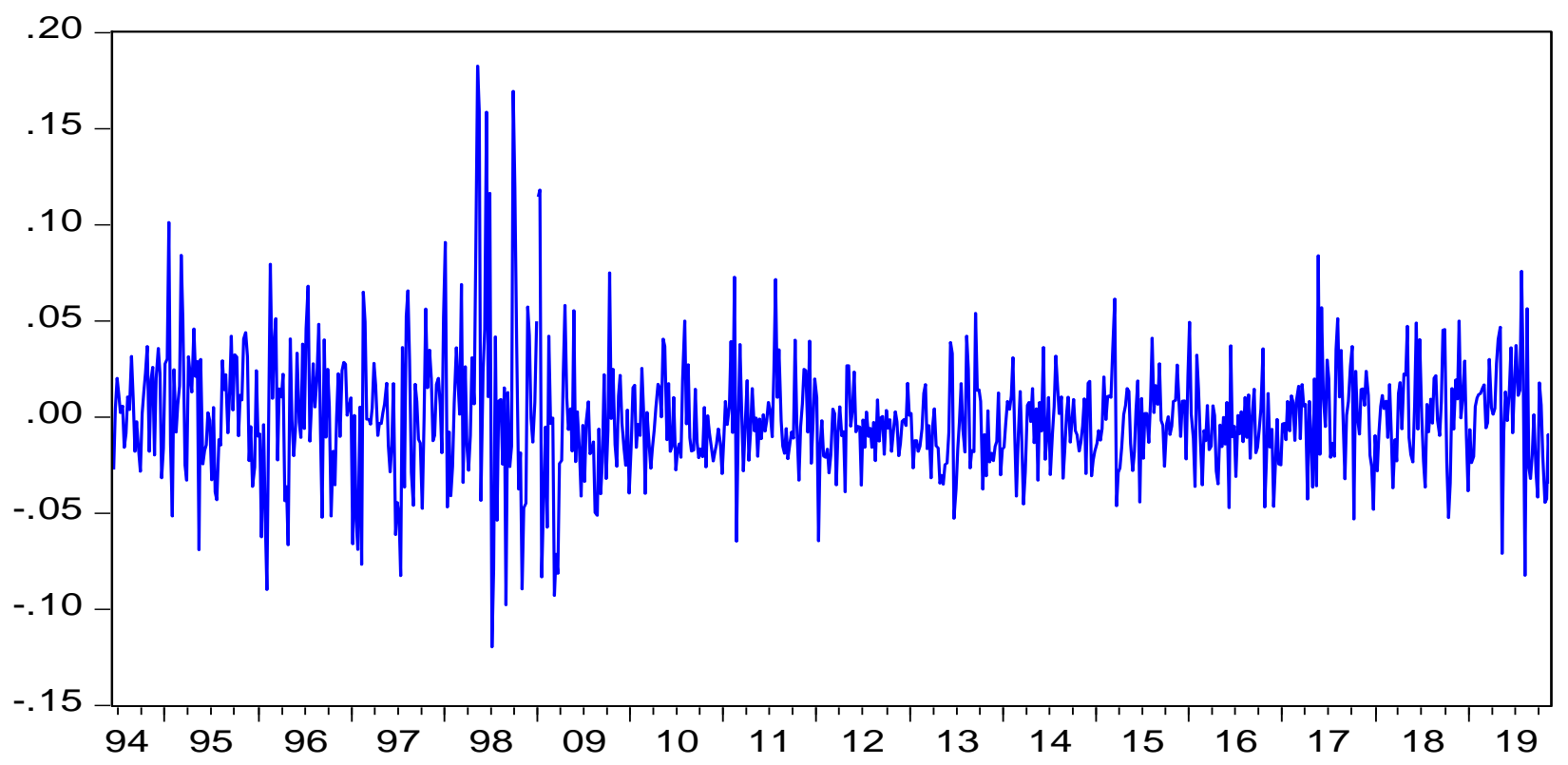

Figure 4. Autocorrelation for democratic phase

\section{Variance Ratio Test Results}

$\mathrm{VR}(\mathrm{q})$ is Variance Ratios for the respective lags. $\mathrm{Z}$ is $\mathrm{z}$-statistics for unbiased variance (Homoscedastic) tests. While $\mathrm{Z}^{*}$ is statistics for heteroskedastic robust standard errors (Heteroskedastic) tests. Numbers in the Joint Tests are the Wald Statistics (Chi-Square). The asterisk $* * *$, and $* * *$ denotes significant levels of $1 \%, 5 \%$, and $10 \%$ respectively as indicated by p-value. Table 3 shows the results of the variance ratio test. The VR test is one of the traditional consumer effectiveness assessment tests. If the logarithm variance of a variable series fits the random walk is also preliminary. $\mathrm{VR}=1$ is for the null hypothesis. VR testing is based on two objective variance estimation tests and robust standard heteroskedastic error estimation. Test months 2, 4, 8, and 12 were chosen as the period for the test. The overall results illustrate that unbiased variance estimation (Homo) is significant at $1 \%$ for the null hypothesis VR $=1$. But heteroskedastic robust standard error estimation (Hetero) is insignificant for the null hypothesis $\mathrm{VR}=1$. In the military phase, the results show that unbiased variance estimation (Homo) is significant at $1 \%$ for the null hypothesis $\mathrm{VR}=1$. Heteroskedastic robust standard error estimation (Hetero) is also significant for the null hypothesis $\mathrm{VR}=1$. In democracy phase results show that unbiased variance estimation (Homo) is significant at $1 \%$ for the null hypothesis VR $=1$. But heteroskedastic robust standard error estimation (Hetero) is insignificant for the null hypothesis $\mathrm{VR}=1$. Table 3 represents variance ratio test results. 
Table 3

Results of Variance Ratio Test

\begin{tabular}{|c|c|c|c|c|c|c|c|}
\hline \multirow[t]{2}{*}{$\begin{array}{l}\text { Sample } \\
\text { Period }\end{array}$} & \multirow[t]{2}{*}{$\begin{array}{c}\text { Test } \\
\text { Specification }\end{array}$} & \multirow[t]{2}{*}{ Statistics } & \multicolumn{4}{|c|}{$\begin{array}{l}\text { Individual } \\
\text { Tests }\end{array}$} & \multirow[t]{2}{*}{$\begin{array}{l}\text { Joint } \\
\text { Tests }\end{array}$} \\
\hline & & & Lag 2 & Lag4 & Lag8 & Lag12 & \\
\hline \multirow{4}{*}{ Overall } & \multirow{3}{*}{ Homo } & $\operatorname{VR}(\mathrm{q})$ & 0.50 & 0.12 & 0.06 & 0.03 & \multirow{2}{*}{$362.33^{*}$} \\
\hline & & $Z(q)$ & $-18.19^{*}$ & $-17.00 *$ & $-11.53 *$ & $-8.01 *$ & \\
\hline & & $\operatorname{VR}(q)$ & 0.49 & 0.12 & 0.063 & 0.03 & \multirow{2}{*}{1.17} \\
\hline & \multirow[t]{2}{*}{ Hetero } & $\mathrm{Z}(\mathrm{q})$ & -1.00 & -1.17 & -1.07 & -1.03 & \\
\hline \multirow{4}{*}{ Military Phase } & & $\operatorname{VR}(q)$ & 0.52 & 0.26 & 0.14 & 0.076 & \multirow{2}{*}{115.18} \\
\hline & \multirow[t]{2}{*}{ Homo } & $Z(q)$ & $-10.7 *$ & $-8.90^{*}$ & $-6.60^{*}$ & $-4.80^{*}$ & \\
\hline & & $\operatorname{VR}(q)$ & 0.52 & 0.26 & 0.13 & 0.067 & \multirow{2}{*}{6.61} \\
\hline & Hetero & $\mathrm{Z}(\mathrm{q})$ & $-6.61 *$ & $-6.04 *$ & $-4.88^{*}$ & $-3.89 *$ & \\
\hline \multirow{4}{*}{$\begin{array}{l}\text { Democracy } \\
\text { Phase }\end{array}$} & \multirow{3}{*}{ Homo } & $\operatorname{VR}(q)$ & 0.50 & 0.12 & 0.06 & 0.03 & \multirow{2}{*}{$220.27 *$} \\
\hline & & $Z(q)$ & $-14.18 *$ & $-13.26 *$ & $-8.99 *$ & -6.24 & \\
\hline & & $\operatorname{VR}(q)$ & 0.49 & 0.12 & 0.06 & 0.03 & \multirow{2}{*}{1.16} \\
\hline & Hetero & $Z(q)$ & -1.00 & -1.16 & -1.07 & -1.03 & \\
\hline
\end{tabular}

\section{Graphical Presentation of Variance Ratio in Homo and Hetero Statistics} Variance Hetero Graph

Figure 5 shows the trend of variance ratio for returns with variance ratio. It shows a mix return in hetero.

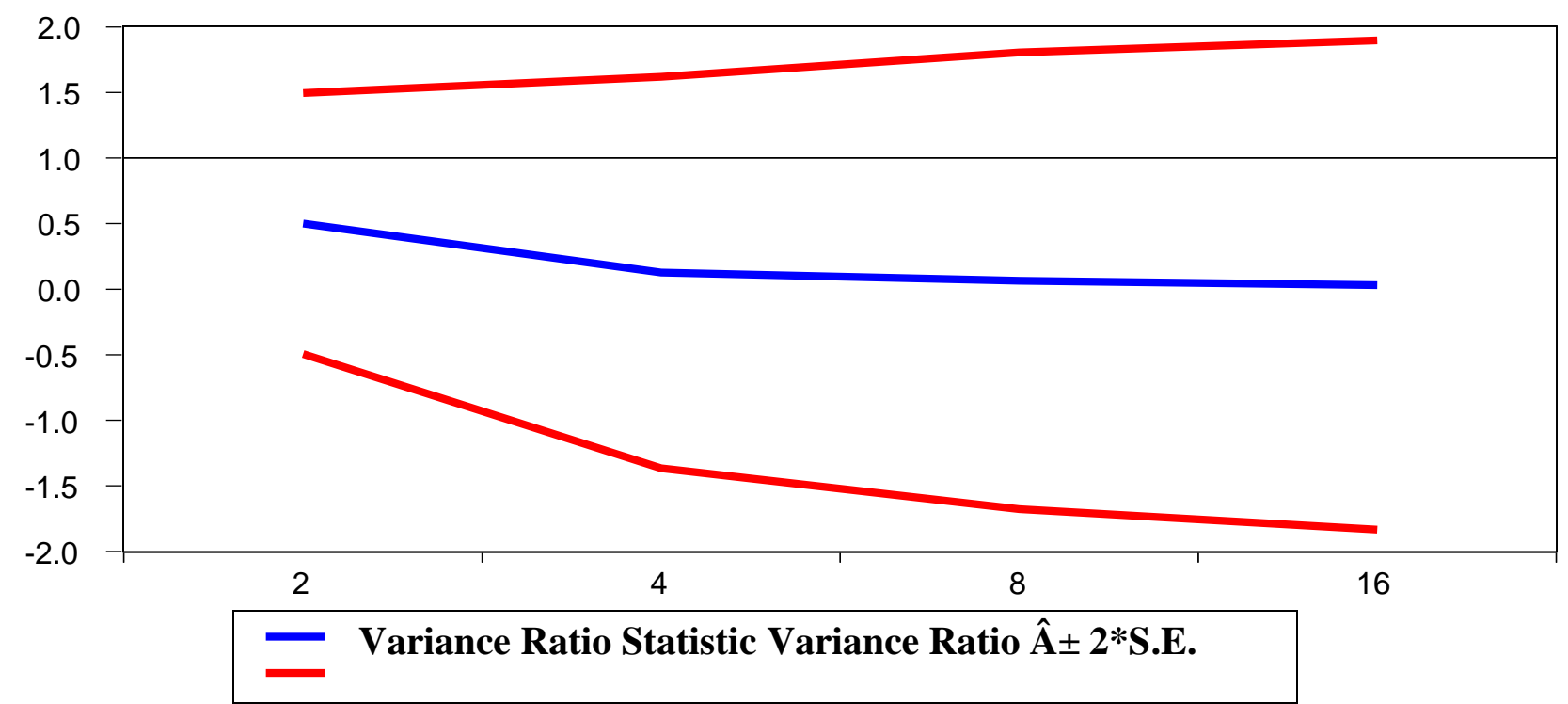

Figure 5. Variance ratio statistic for returns in hetero 


\section{Variance Homo Graph}

Figure 6 shows the trend of variance ratio for returns with variance ratio. It shows a mix return for homo.

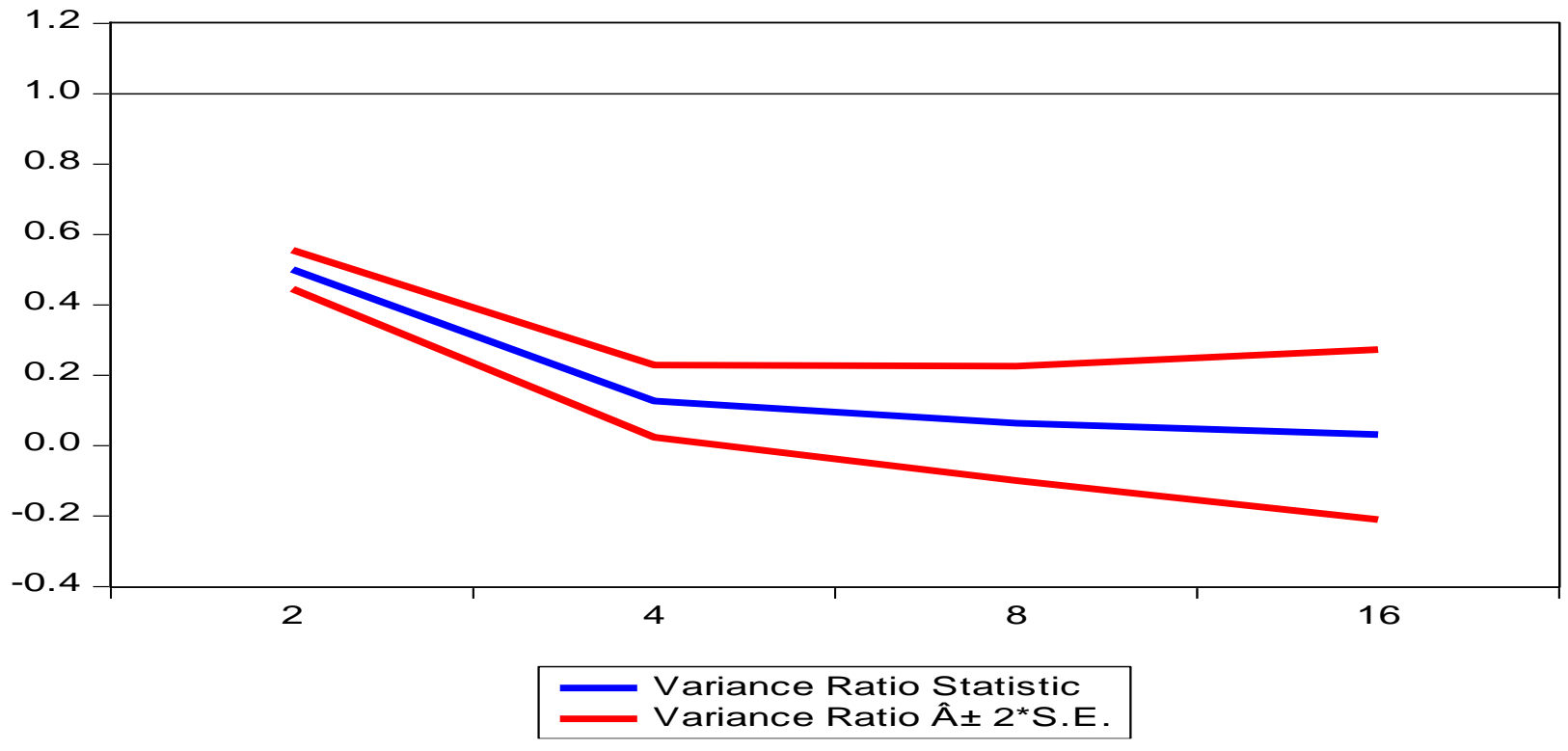

Figure 6. Variance ratio statistic for returns in homo

\section{Summary of Weak-Efficiency Tests}

The results of the weak efficiency test for weak efficiency level for lags 2 are shown in Table 4 . Results suggest that the market operates under low performance. This also indicates that, with the number of lags increasing, the degree of market efficiency decreases. Table 4 shows the summary of results.

Table 4

Summary of Weak-Efficiency Tests

\begin{tabular}{llll}
\hline Test/Conditional & Overall & Military Phase & Democracy Phase \\
\hline \multirow{2}{*}{ AR } & No Autocorrelation & autocorrelation & No Autocorrelation \\
& Present & Present & Present \\
& (un Predictable) & (un Predictable) \\
VR $($ Hetero) & 0.49 & 0.52 & 0.49 \\
& $(>0.5)$ & $(<0.5)$ & $(>0.5)$ \\
\hline
\end{tabular}

\section{Summary of Analysis}

The efficiency of the Pakistan Stock Market (PSX) is considered using autocorrelation at lag that imitates the informational efficiency clearly. The analyses are executed on segmented data. In the overall period and Democratic phase series there is no autocorrelation through the previous standards which remain insignificant in addition to gradually rises as the integer of intervals escalations while in the segmented data Military Phase autocorrelation is statistically present which shows the market efficiency is improved. The facts of the adaptive performance of market competence calculations established on specific intervals and combined investigations for all intervals which remain mentioned in Table 4. The market competence is also examined by the help of the variance ratio (VR) test. VR is lead constructed upon dual assessments one is impartial alteration valuation and heteroskedastic robust standard error estimation Test months 2, 4, 8, and 12 are chosen as the period for the test. The VR test for segmented data is changed. The overall results show that unbiased variance estimation (Homo) is significant at $1 \%$ for the null hypothesis 
$\mathrm{VR}=1$. But heteroskedastic robust standard error estimation (Hetero) is insignificant for the null hypothesis $\mathrm{VR}=1$. In the military phase, the results show that unbiased variance estimation (Homo) is 21 significant at $1 \%$ for the null hypothesis VR $=1$. Heteroskedastic robust standard error estimation (Hetero) is also significant for the null hypothesis VR $=1$. In democracy phase results show that unbiased variance estimation (Homo) is significant at $1 \%$ for the null hypothesis $\mathrm{VR}=1$. But heteroskedastic robust standard error estimation (Hetero) is insignificant for the null hypothesis VR $=1$.

\section{Discussion}

Behavioral finance is the study of the influence of the psychological factors on financial market evolution. In other words, the financial market's inefficiency is analyzed in light of the psychological theories and perspectives. Behavioral finance is a relatively recent and high impact paradigm which provides an interesting alternative to classical finance. Classical finance assumes that capital markets are efficient, investors are rational and it is not possible to outperform the market over the long-term. Behavioral finance's psychological principles include heuristics and biases, overconfidence, emotion, and social forces, among others. Considering its financial identity is a very important step for an investor. In other words, knowing why you make such financial decisions or how you are likely to respond under specific conditions of uncertainty is vitally important in an investor's position. This method of analysis is helpful when trying to understand how to balance the irrational components of investment decisions while at the same time fulfilling the individual desires and needs. Behavioral finance gives a special, very nuanced, and unorthodox viewpoint. The behavioral finance paradigm suggests that psychological and emotional factors influence investment decisions in a large proportion. The following primary emotions include human emotional complexity: terror, panic, anxiety, envy, euphoria, greed, pride, ambition, or vanity. Very likely all of these emotions interfere in a financial investment decision-making process in some proportions (Birău, 2012). Conversely, behavioral finance believes that financial markets are informational inefficient in some situations.

The efficient market hypothesis $(\mathrm{EMH})$ is of the opinion that when investors look for alternative solutions Stock market vogue, each investor is acting in a very divergent way. Effective Market theory moves the market towards optimal competition in which no investor can long-term manipulate the market. A market is effective with respect to a collection of information because it is difficult to make economic gains by investing on the basis of this set of information (Ross, 1987). Behavioral finance is a modern approach to capital markets, playing a significant role in the process of financial decision-making. Behavioral finance decision-making can be defined as the process of selecting a particular investment alternative from a variety of options. It is an operation that occurs after all alternatives have been thoroughly evaluated (Hu \& Mathews, 2005). The cognitive psychology-focused behavioral finance model suggests that the investment decision cycle can be efficiently evaluated using the following variables: overconfidence, herding complex, overreaction, protectionism, preconceived ideas, over-optimism, representativeness, irrationality or logical thought, and media channel effect. In financial theory, behavioral finance represents a revolution. Combining finance theory with other ideas, the social sciences gave rise to behavioral finance. This is a fairly young and exciting new finance market that has notable progress over the last few decades. Behavioral finance illustrates the psychological dimension of the investment decisionmaking process, in sharp contrast to the theory of Efficient markets. 
Prospect theory probably had more impact on economic research than any other behavioral theory. It is quite popular given the fact that a significant part of the economics field is still regarded as a whole and has a distinct prominent theory for most work. The essential theoretical aspect is the results on the prospect model by Kahneman and Tversky (2013), which anticipated a clear good judgment of exactly how relevant is the role played by that model in economic exploration. Thanks to the difficulties inherent in applying prospect theory, we are making strides in development over the last few years. Since 1994-2018 the analysis is focused on the segments called Overall, Military Phase, and Democratic Phase. The result indicates a dynamically important risk divergence, and next to those phases returns properties. They conclude the essence of Pakistan's evolving stock market competence level through the various segments referred to as the overall Military Phase and Democracy Phase with AMH reference, it seems that the evolving competence is due to the changing output of stakeholders. That is sensitive to adjusting the arrangements of the facts and different circumstances.

Business competence in the military segment shows to be evolving as compared with Democracy and overall time. The results are aligned with good references showing that the liberalization of the financial market contributes to the overall improvement of the economy and the sharing of skills, market fusion, and statistics expertise in the monetary markets. For both VR (Homogenous and Hetero) experiments, it is realistic that the stock return pattern is important for the military process. This implies good performance. The significance of the military phase autocorrelation test predicted the capability figure of stock yields using its preceding proof. Based on the hypothesis, we also found that the objective of variance estimation (Homo) is important at 1 percent for the null hypothesis VR $=1$ in both the democratic process and overall results. But for the null hypothesis which follows EMH's weak efficiency pattern, heteroskedastic robust standard error estimation (Hetero) is insignificant. The results suggest that monetary capital estimates (current asset values) do not match the central requirements of such comparable monetary assets. Individuals do not behave in compliance with neoclassical rules when such activity is needed to strengthen the rapid convergence of market prices and the critical asset requirements being investigated. Behavioral economists disagree that vision model reliefs give details of the financial 's propensity to grip scheduled and to reduce portions targeting lengthy and trade-engaging stocks too rapidly. It is referred to as the effect on nature (Shefrin \& Statman, 1985; Shiller, 1999). This influence follows the assumption that individuals tend to observe a threat on an ordinary basis and that individuals tend to be threatening to observe damage and risk-averse in accomplishments on ordinary. There are three main trends of behavioral finance, according to some experts, such as Shefrin Economy:

- Heuristics: Investors frequently decide on the basis of approximate thumb rules, without depending on a logical reasoning Framing: The selection of stories and stereotypes comprises human mental emotional filters.

- It depends on knowing and reacting to happenings.

- Market inefficiencies: these include mispricing, unfair decision-making, and the phenomena return.

In a world of uncertainty, decisions are made for many people driving to hang on to forgetting stocks expecting the value of such stocks to recover in the direction of purchasing value (risk search). Different individuals resolve to swap relatively high-valued fiscal assets too quickly being afraid of such assets to decline in value. According to the predictable perspective, in a world where 
there are no funds acquiring duties, the more balanced option will be for those grasping stocks to accomplish further expansions and dropping stocks to trade in order to avoid growing harm. In comparison, in a world where future risks cannot be certainly intentional (Knightian uncertainty), forming as soon as stocks are exchanged or recovered. It is not consistently high given the difficulty of predicting future financial asset prices or assessing operations at those levels. Therefore, this situation is basically balanced action (utilities-maximizing) acting in accordance with prospect theory effect. In addition, if such ambiguity and the presence of irregular evidence are presumed, a lot of people will invest choices built on collecting which wanted to reinforce the outcome of nature. Perhaps those will be preferred to sell, purchase, or retain financial assets following a multitude of actions or the creation of the economy. These actions would result in significant and profound fluctuations in the valuation of financial assets, which would create financial bubbles which statues.

Eugene, Fama and French (1993) demonstrated the scope and value as mutual risk aspects which can describe the difference in return on stock returns. Insignificant stocks are insecure too. Therefore, they have to reimburse on behalf of the risk. Usual financiers escalate demands for large organizations' stocks by anticipating developed future returns, and these stocks costly convert on the stock market. Complex stock prices result in lower yields besides complicated higher-risk factors and the distance affects stock returns destructively. Financiers are becoming significantly positive and assured for shares requiring extraordinary market capitalization (Finter, NiessenRuenzi, \& Ruenzi, 2012; Statman, 2014). Eugene, Fama and French (1993) found that quantity and cost variables together explain cross-section differences in expected returns. The quick return of a limited stock is known reasonably vice versa after a behavioral interpretation. Stocks with a low volume to equity ratio are known as interesting stocks because they are regarded by financiers as a virtual opportunity to capitalize on them. Financiers express visions about future returns through the generalization of historical return sequences (Barberis, Greenwood, Jin, \& Shleifer, 2015). However, these overestimated stocks yield a smaller return on stock devalue assessment (Statman, 2014).

Additional return accumulated by significant organizations is highly sufficient to be explained by the risk factor of the market (Eugene, Fama \& French, 1993). Irrational traders drive up market prices of top stocks of book-to-market securities by rising their demand for these stocks. Incorrect expectations from financials result in higher receipt of worthy stocks and lower earnings for stocks of curiosity. Long-term difficulty inspected by De Bondt and Thaler (1985), associates with the hypothesis of overreaction. They proclaimed that financials would exaggerate to unexpected and dramatic news acts. Their assessments help us in appreciating why previous 'victors' and 'failures' earned a return in January month. Any possible explanation of the effects of the impetus in stock returns, overreaction occurs (Byun, Lim, \& Yun, 2014). Victor stocks generate greater earnings than failed stocks (Jegadeesh \& Titman, 1993, 2001).

\section{Conclusion}

This research examined Pakistan stock market Returns data from June 1994 to December 2018 alienated in segments economically are named as Military phase (1999-2008) and Democratic phase (1994-1998) (2009-2018). In this research, Autocorrelation, variance ratio tests are conducted on the stock returns (weekly based) KSE 100 index with an adaptive arrangement of market effectiveness crosswise in both stages. This research elaborates on the strong form of competence of the Pakistan stock market-consuming KSE-100 Index, followed the refined 
alteration ratio test in accumulation to the autocorrelation analysis during the democratic phase and EMH during the Military phase. Accordingly, the Autocorrelation test and variance ratio analysis established the occurrence of irregular active performance of returns obviousness in accumulation to risk and return relationships across segmented data. Additionally, these indications provide sustenance to the restricted adaptive rationale of financiers' behavior, passionate stock return behavior, and therefore establishing restricted adaptive market competence. Autocorrelation tests show the difference in all segments. The overall and democracy results are insignificant indicating that there is no autocorrelation among a sequence of returns and its lagged importance for the null hypothesis $\mathrm{AR}=0$. While in the military phase the results are significant specifying that there is a autocorrelation between the sequences of returns and its lagged importance for the null hypothesis $\mathrm{AR}=1$. After that, the Variance Ratio test was examined whether the variance of logarithms of an adjustable sequence follows the unsystematic stride. For this, the null hypothesis is VR $=1$. VR test is constructed on dual examinations impartial modification valuation and heteroskedastic robust standard error valuation. Test months 2, 4, 8, and 12 were chosen as the period for the test. The overall results show that unbiased variance estimation (Homo) is significant at $1 \%$ for the null hypothesis $\mathrm{VR}=1$. But heteroskedastic robust standard error estimation (Hetero) is insignificant for the null hypothesis $\mathrm{VR}=1$. In the military phase, the results show that unbiased variance estimation (Homo) is significant at $1 \%$ for the null hypothesis $\mathrm{VR}=1$. Heteroskedastic robust standard error estimation (Hetero) is also significant for the null hypothesis VR $=1$. In democracy phase, results show that unbiased variance estimation (Homo) is significant at $1 \%$ for the null hypothesis $\mathrm{VR}=1$. But heteroskedastic robust standard error estimation (Hetero) is insignificant for the null hypothesis $\mathrm{VR}=1$. The study enclosed a vast gap as the previous workup is done at diverse edges and variables for calculating Pakistan's stock market efficiency. This is a unique sort of work in Pakistan which has segmented data based by taking KSE 100 INDEX as the dependent variable.

\section{References}

Ackert, L., \& Deaves, R. (2009). Behavioral finance: Psychology, decision-making, and markets. Cengage Learning. https://www.cengage.com/c/behavioral-finance-psychology-decision-making-and-markets-1e-ackert/9780324661170

Avramov, D., \& Chordia, T. (2006). Asset pricing models and financial market anomalies. The Review of Financial Studies, 19(3), 1001-1040.

Bai, J., \& Ng, S. (2005). Tests for skewness, kurtosis, and normality for time series data. Journal of Business \& Economic Statistics, 23(1), 49-60.

Barberis, N., Greenwood, R., Jin, L., \& Shleifer, A. (2015). X-CAPM: An extrapolative capital asset pricing model. Journal of Financial Economics, 115(1), 1-24.

Barberis, N., Shleifer, A., \& Vishny, R. (1998). A model of investor sentiment. Journal of Financial Economics, 49(3), $307-343$.

Baumol, W. J. (1965). The stock market and economic efficiency (No. 6). Fordham University Press.

Birău, F. R. (2012). The impact of Behavioral finance on stock markets. Annals-Economy Series, 3, 45-50.

Byun, S. J., Lim, S. S., \& Yun, S. H. (2014). Continuing overreaction and stock return predictability. Journal of Financial and Quantitative Analysis. Forthcoming, Available at SSRN: https://ssrn.com/abstract=2023158 or http://dx.doi.org/10.2139/ssrn.2023158 
Campbell, J. Y., Grossman, S. J., \& Wang, J. (1993). Trading volume and serial correlation in stock returns. The Quarterly Journal of Economics, 108(4), 905-939.

Chen, H. Y., Chou, P. H., \& Hsieh, C. H. (2018). Persistency of the momentum effect. European Financial Management, 24(5), 856-892.

Daniel, K., Hirshleifer, D., \&Subrahmanyam, A. (1998). Investor psychology and security market under-and overreactions. Journal of Finance, 53(6), 1839-1885. https://onlinelibrary.wiley.com/doi/abs/10.1111/0022-1082.00077

De Bondt, W. F., \& Thaler, R. (1985). Does the stock market overreact?. The Journal of Finance, 40(3), 793-805.

Eugene, F., Fama, E. F., \& French, K. R. (1993). Common risk factors in the returns on stocks and bonds. Journal of Financial Economics, 33, 3-56.

Fama, E. F. (1965). The behavior of stock-market prices. The journal of Business, 38(1), 34-105.

Fama, E. F. (1970). Efficient capital markets: A review of theory and empirical work. The journal of Finance, 25(2), 383-417.

Finter, P., Niessen-Ruenzi, A., \& Ruenzi, S. (2012). The impact of investor sentiment on the German stock market. Zeitschrift für Betriebswirtschaft, 82(2), 133-163.

Hong, H., \& Stein, J. C. (2007). Disagreement and the stock market. Journal of Economic Perspectives, 21(2), 109-128.

Hu, M. C., \& Mathews, J. A. (2005). National innovative capacity in East Asia. Research Policy, 34(9), 1322-1349.

Huang, Z., Heian, J. B., \& Zhang, T. (2011). Differences of opinion, overconfidence, and the high-volume premium. Journal of Financial Research, 34(1), 1-25.

Irfan, M., Irfan, M., \& Awais, M. (2010). Investigating the weak form efficiency of an emerging market by using parametric tests: evidence from Karachi stock market of Pakistan. Electronic Journal of Applied Statistical Analysis, 3(1), 52-64.

Jegadeesh, N., \& Titman, S. (1993). Returns to buying winners and selling losers: Implications for stock market efficiency. The Journal of Finance, 48(1), 65-91.

Jegadeesh, N., \& Titman, S. (2001). Profitability of momentum strategies: An evaluation of alternative explanations. The Journal of Finance, 56(2), 699-720.

Kahneman, D., \& Tversky, A. (2013). Prospect theory: An analysis of decision under risk. In Handbook of the fundamentals of financial decision making: Part I (pp. 99-127).

Kim, K. A., \& Nofsinger, J. R. (2008). Behavioral finance in Asia. Pacific-Basin Finance Journal, 16(1-2), 1-7.

Lo, A. W. (2004). The adaptive markets hypothesis. The Journal of Portfolio Management, 30(5), 15-29.

Lo, A. W., \& MacKinlay, A. C. (1988). Stock market prices do not follow random walks: Evidence from a simple specification test. The Review of Financial Studies, 1(1), 41-66.

Lo, A. W., \& MacKinlay, A. C. (1990). An econometric analysis of nonsynchronous trading. Journal of Econometrics, 45(1-2), $181-211$.

Meier, C. (2014). Adaptive market efficiency: review of recent empirical evidence on the persistence of stock market anomalies. Review of Integrative Business and Economics Research, 3(2), 268-280.

Omar, M., Hussain, H., Bhatti, G. A., \& Altaf, M. (2013). Testing of random walks in Karachi stock exchange. Finance Management, 54, 12293-12299.

Quiggin, J. (1982). A theory of anticipated utility. Journal of Economic Behavior \& Organization, 3(4), 323-343.

Rabbani, S., Kamal, N., \& Salim, M. (2013). Testing the weak-form efficiency of the stock market: Pakistan as an emerging economy. Journal of Basic and Applied Scientific Research, 3(4), 136-142.

Reilly, F. K. C., \& Brown. (2003). Investment Analysis and Portofolio Management. Cengage Learning.

Ross, S. A. (1987). The interrelations of finance and economics: Theoretical perspectives. The American Economic Review, 77(2), 29-34.

Sapusek, A. (1998). Fundamental performance of initial public offerings: empirical evidence from Germany. Martin-LutherUniversität Halle-Wittenberg, Wirtschaftswissenschaftliche Fakultät.

Shefrin, H. (2001). Behavioral corporate finance. Journal of Applied Corporate Finance, 14(3), 113-126.

Shefrin, H., \& Statman, M. (1985). The disposition to sell winners too early and ride losers too long: Theory and evidence. The Journal of Finance, 40(3), 777-790.

Shiller, R. J. (1999). Human behavior and the efficiency of the financial system. Handbook of Macroeconomics, 1, $1305-1340$.

Soufian, M., Forbes, W., \& Hudson, R. (2014). Adapting financial rationality: Is a new paradigm emerging?. Critical Perspectives on Accounting, 25(8), 724-742. 
Smith, G., \& Ryoo, H. J. (2003). Variance ratio tests of the random walk hypothesis for European emerging stock markets. The European Journal of Finance, 9(3), 290-300.

Statman, M. (2014). Behavioral finance: Finance with normal people. Borsa Istanbul Review, 14(2), 65-73.

Statman, M., Fisher, K. L., \& Anginer, D. (2008). Affect in a behavioral asset-pricing model. Financial Analysts Journal, 64(2), 20-29.

Tversky, A., \& Kahneman, D. (1992). Advances in prospect theory: Cumulative representation of uncertainty. Journal of Risk and Uncertainty, 5(4), 297-323.

Uhl, M. W. (2014). Reuters sentiment and stock returns. Journal of Behavioral Finance, 15(4), 287-298.

Verardo, M. (2009). Heterogeneous beliefs and momentum profits. Journal of Financial and Quantitative Analysis, 795-822.

Verheyden, T., De Moor, L., \& Van den Bossche, F. (2015). Towards a new framework on efficient markets. Research in International Business and Finance, 34, 294-308.

Watanabe, A., Xu, Y., Yao, T., \& Yu, T. (2013). The asset growth effect: Insights from international equity markets. Journal of Financial Economics, 108(2), 529-563.

Worthington, A., \& Higgs, H. (2004). Random walks and market efficiency in European equity markets. The Global Journal of Finance and Economics, 1(1), 59-78.

Zahid, F. M., Ramzan, S., \& Ramzan, S. (2012). A parametric and non-parametric approach for testing random walk behavior and efficiency of Pakistani stock market. International Journal of Science and Technology, 2(5), 316-322. 